\title{
MEDICINAL GOLD COMPOUNDS
}

\author{
R. V. Parish and Stephanie M. Cottrill \\ Department of Chemistry, The University of Manchester Institute of Science and \\ Technology, Manchester M60 1QD, United Kingdom
}

\begin{abstract}
A major use of gold compounds in the pharmaceutical industry is for antiarthritic agents. The disease itself is not understood and little is known about the way in which the drugs act, but detailed pictures of the distribution of gold in the body are available, and some of the relevant biochemistry is beginning to emerge.
\end{abstract}

Gold is normally present in human and animal tissues in only minute proportions. The the element has no known natural biological function, although some algae are able to absorb considerable quantities of gold from solution and there is one plant species known to concentrate the metal. Many gold compounds are highly toxic to animals, especially chloroauric acid and its salts, largely because of their oxidising ability. Nevertheless, gold and its compounds have a long history of medical application (1). In this century, a few gold compounds have been used very successfully in the treatment of rheumatoid arthritis (2). In the last year, a new compound has been approved for general use in this field (3), and another new material shows promise as an anti-tumour agent (4). As might be expected for drugs containing a heavy metallic element which has no natural function, there are some side effects, notably skin rashes, diarrhoea and nephrosis, and some patients cannot tolerate this form of treatment $(5,6)$. Those who can, however, may well experience actual remission of the disease.

Very little is known about the way in which the goldcontaining drugs act. This is partly because the origin of rheumatoid arthritis is itself not understood, but also because the biological chemistry of gold has been little studied. Indeed, despite intensive work over the last few years, even the precise details of the molecular structures of the established drugs themselves remain obscure; if attempts were being made to introduce them today as new drugs, it is unlikely that their use would be sanctioned.

The purpose of this article is to give a survey of the types of compounds presently employed in medicine, of the distribution of gold in the body which results from their use, and of some relevant chemistry. Emphasis is placed on results obtained in the last few years; other reviews give good coverage of earlier work $(7,8)$.

\section{The Drugs}

The effective compounds are all gold(I) thiolates, that is, they involve AuSR units, where $\mathrm{R}$ is a suitable organic group. There are several practical reasons for this choice. First, the gold should be univalent, to avoid the toxicity associated with the oxidising power of the more normal trivalent state. Second, in order to stabilise the gold(I) against disproportionation into inactive elemental gold and toxic gold(III), the gold must be bound to groups (ligands) with which it can form strong covalent bonds. These ligands must therefore be 'soft', i.e. bound to gold through atoms of relatively low electronegativity, such as sulphur, phosphorus or carbon - the 'harder' oxygen, nitrogen and halogens will not do. These soft ligands also give the compounds good stability 'on the shelf'. Third, the ligands must not be so tightly bound, nor the compounds so stable, that metabolic reactions will not occur. Such reactions are likely to be the means by which the gold is transported within the body, and are certainly the cause of the therapeutic activity.

Thiolates meet these criteria well. In the traditional antiarthritics they are the sole ligands, so the drugs have the general formula AuSR. The two most commonly used 
compounds are those in which the organic group is a sugar (Solganol) or the salt of a dicarboxylic acid (Myocrisin).
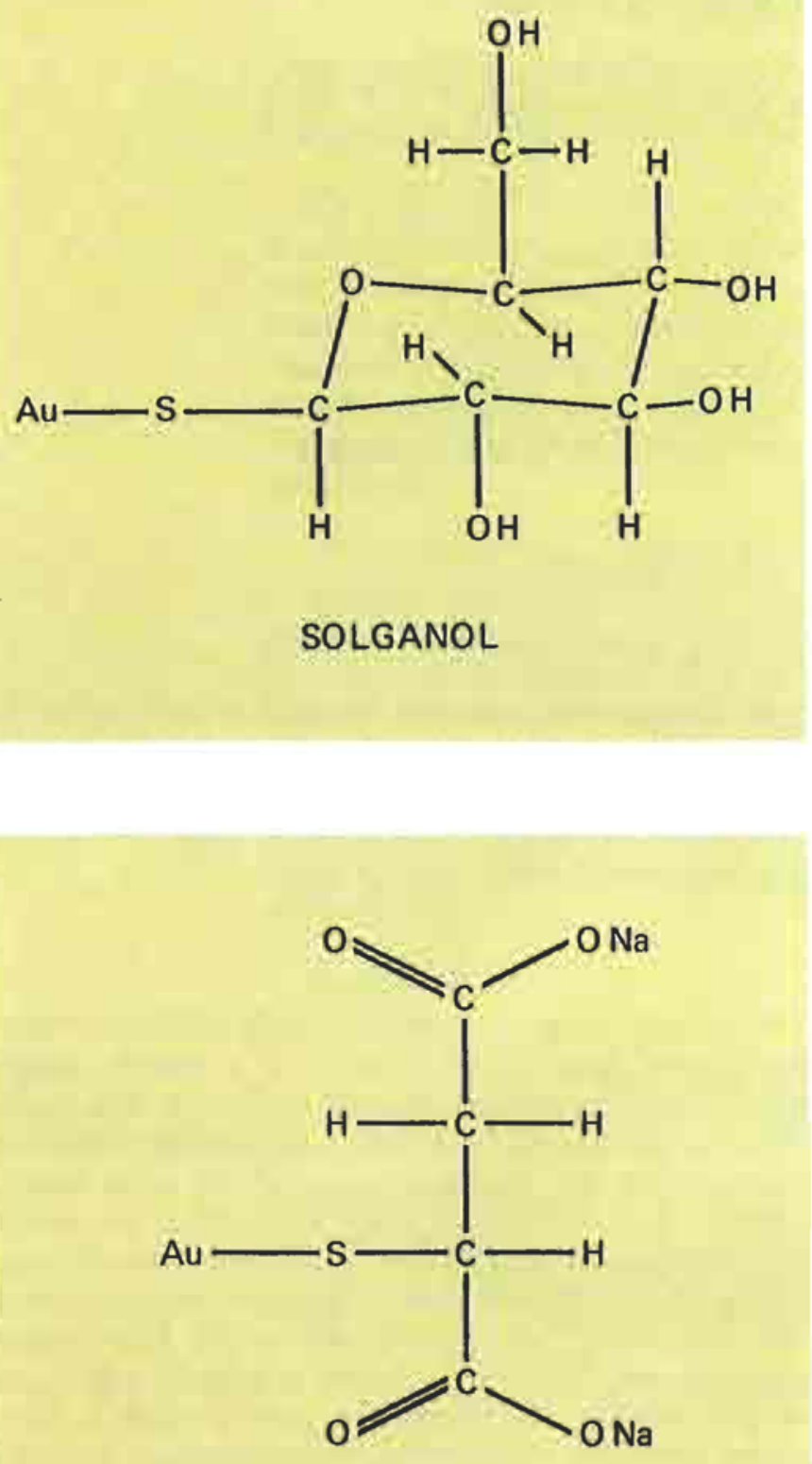

MYOCRISIN

The use of these groups means that the compounds are soluble in water, and they are administered by injection of a solution. The solid compounds are usually obtained as amorphous powders, and crystals suitable for X-ray examination have never been obtained. The precise molecular structures have therefore not yet been established. Data from a variety of other techniques indicate polymeric structures in which the sulphur atoms form bridges between adjacent gold atoms (9-14). Each gold atom is therefore bound to two sulphur atoms:

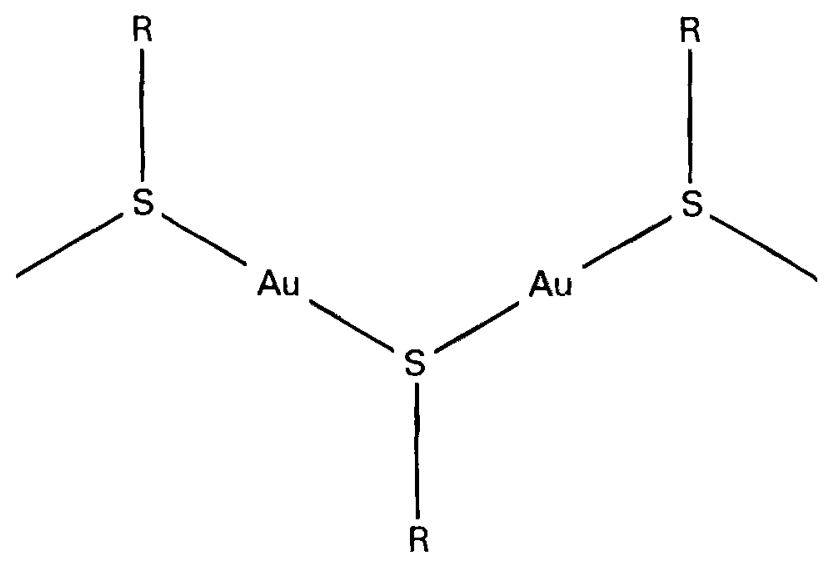

This form of linear coordination is very common fos gold(I). Structures involving these units could be closer rings or open chains; both forms are known for analogou: silver(I) thiolates, depending on the size and shape of the $F$ group and, sometimes, on whether the solid or its solution is examined (15-17). Very recently, data from wide-anglı scattering and absorption-edge fine structure mea surements with X-rays (WAXS and EXAFS) have bee1 interpreted in favour of the linear structure both for solin Myocrisin and for its aqueous solutions (18). Such a struc ture requires the presence of an 'extra' thiolate ligand $t_{1}$ cap the 'bare' gold atom at the end of each chain, and it ha been noted that conventional preparations of Myocrisi contain a slight excess of thiomalate (19).

The newly introduced compound Auranofin (c Ridaura) involves an acetylated thioglucose group. How ever, this compound is monomeric by virtue of the presenc of a phosphine ligand, so that the coordination of the gol is P-Au-S.

This compound can be readily crystallised, and its structur in the solid state is accurately known (20). Both it and it immediate metabolite (the de-acetylated form) (21) at only sparingly soluble in water, but they have good lipi solubility, and can be absorbed through the intestin Auranofin is therefore administered orally as the solid. ] 


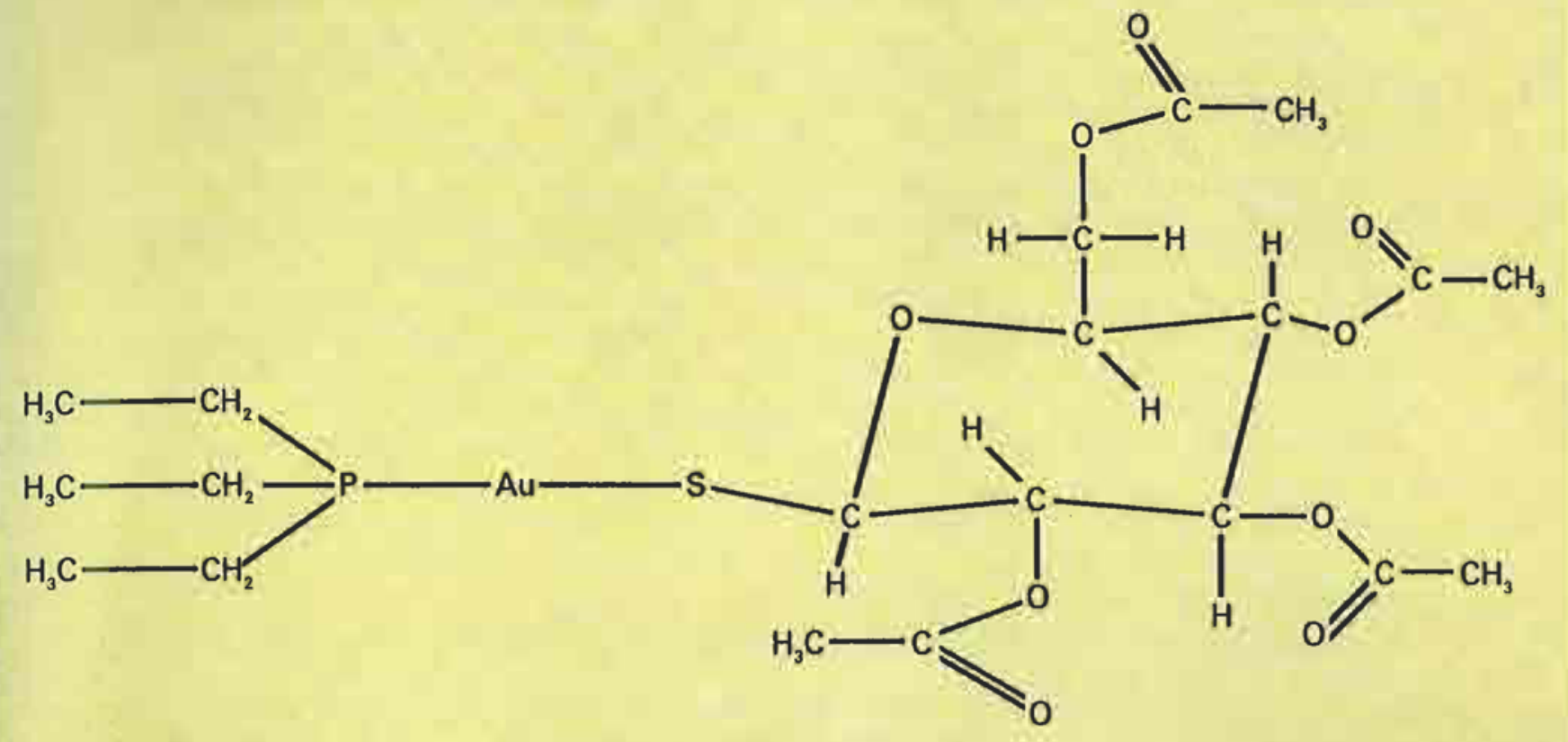

AURANOFIN

this form, only 20-25 per cent of each dose is absorbed into the body, the remainder being eliminated faecally (22). Recent animal studies show that administration of a solution in 5 per cent aqueous alcohol leads to effectively complete uptake of the drug (23).

Some workers believe that it is the thiolate part of the drug which is the active entity, and that the gold compounds serve only as a means of introducing them into the body. Analogies have been drawn between the molecular structure of Myocrisin and penicillamine, which has also been used to treat arthritis (24-26). Sodium thiomalate itself does have slight efficacity against rheumatoid arthritis, but has to be given in considerably larger doses than Myocrisin (27). A wide variety of gold compounds has now been shown to be active, including some which possess no thiolate ligands at all, so the metal can be identified as the common therapeutic factor. As indicated above, it is the role of the ligands to stabilise and carry the gold.

\section{Distribution and Metabolism}

The two types of drugs are administered differently. Auranofin has the advantage that it can be taken like conventional medicines, by mouth; doses of $2.5 \mathrm{mg}$ per day are normal. Unfortunately, if Myocsrisin or Solganol are given in this way, they are promptly and drastically eliminated. Administration is therefore by injection of an aqueous solution, usually in the gluteal muscle, at weekly doses of 25$50 \mathrm{mg}$. Since the treatment is long-term, the patients receive comparable amounts of gold whichever type of drug is used. However, because solid Auranofin is rather inefficiently absorbed, the actual effective dose is considerably less.

After administration, the drug will begin to be absorbed and metabolised. It is important to realise that the species which exerts the actual therapeutic effect may, in a chemical sense, be very different from the drug itself. This is true of all drugs, but especially those containing metallic elements. To understand how the drugs work (and the origin of unwanted side effects) it is necessary to study their metabolism. However, before this can be attempted, knowledge is needed of the way in which the administered gold moves around the body. That is, the concentration of gold in various organs, tissues, and body fluids must be measured over periods of several days or, preferably, weeks.

Two major methods are available. The first is direct analysis of samples by methods such as neutron activation or atomic absorption. These techniques can be readily ap- 

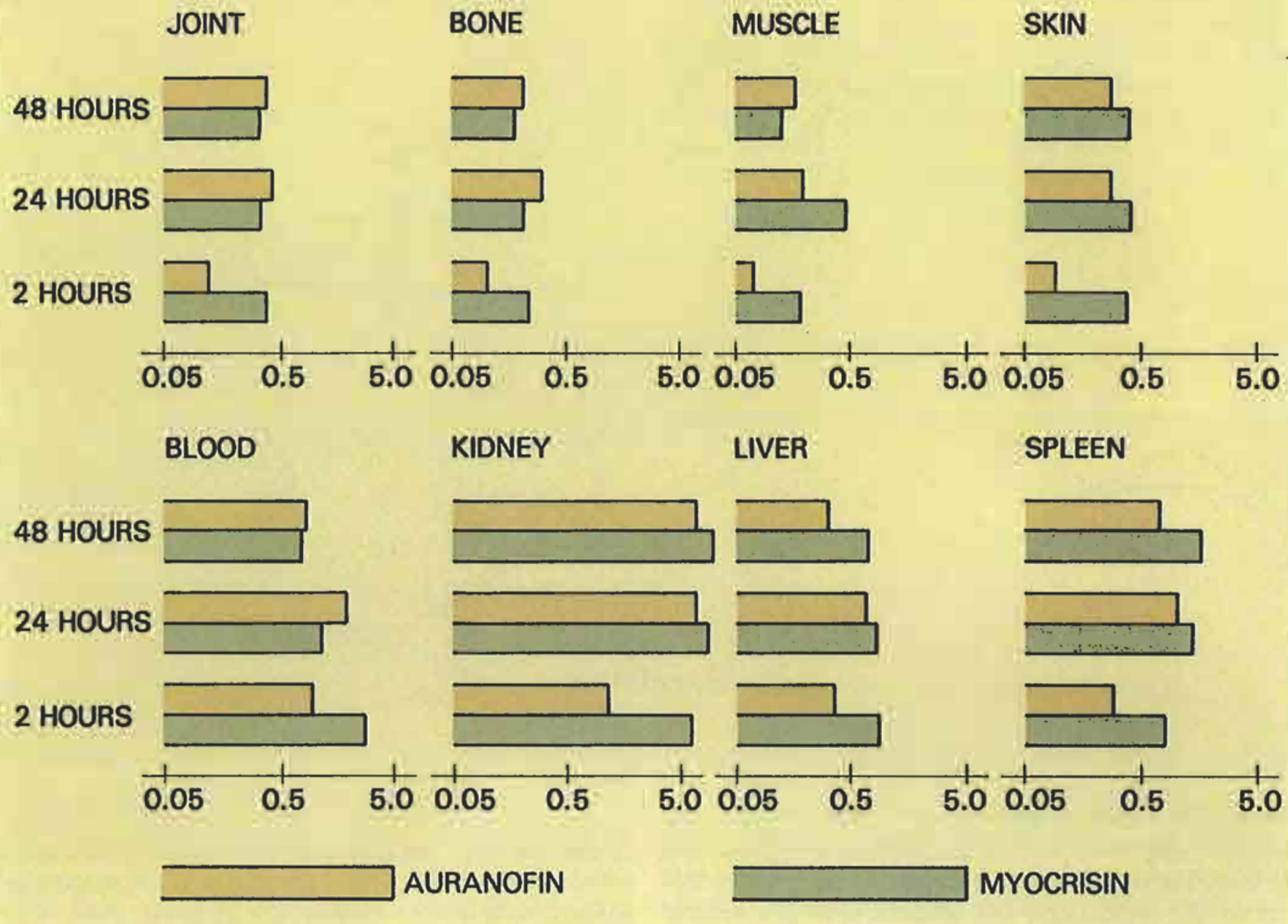

Tig. 1 Distribution of gold in various organs of rats after adninistration of Myocrisin or Auranofin at $2.5 \mathrm{ng} / \mathrm{kg}$. Note that the horizontal seale is logarithnic

plied to blood or excrement, for which samples can be obtained easily without harm to the patient. Other organs are generally available only post mortem or after surgery. A better method, in principle at least, is to use radioactive isotopes of gold. Approximate distribution patterns can be obtained by monitoring the radiation externally to the body, but accurate results can again be obtained only by taking surgical samples of the organs, etc. In consequence, the most detailed studies have been made with animals: rats, mice, guinea pigs, and dogs have all been used. Fortunately, these data seem broadly to parallel those for humans (28).

The results of a recent detailed comparison of Myocrisin and Auranofin in rats (23) are shown in Figure 1.
The data were obtained by preparing samples of the drugs containing radioactive gold-199, which were administered at doses comparable with those normally given to human patients. It is evident that, after about 24 hours, there are no major differences in the distribution of gold from the two drugs, despite the differences in their molecular structure and in the mode of administration.* However, it is also

* It should be noted that, in this trial, Auranofin was given by mouth but was in solution. This led to effectively complete uptake of the drug, rather than the ca. 20\% which is nomal when the solid drug is administered. In other studies, therefore, the amounts of gold recorded are 4-5 times less for Auranofin than shown here. 
obvious that Myocrisin is absorbed almost instantly into the blood stream, by which it is rapidly transported throughout the body. Clearance of gold from the blood by kidney, liver and spleen begins immediately, and the blood level drops accordingly. In contrast, gold from Auranofin is adsorbed only slowly. Clearly, some metabolic reactions have to occur before the drug can pass through the stomach or intestinal wall, and it has been shown that this is almost certainly the removal of the acetyl groups from the thioglucose unit (21). Once in the blood, the gold is removed by the kidney, liver and spleen, just as for Myocrisin. The levels attained in these organs are about two times lower than those from Myocrisin (and lower still when solid Auranofin is used), giving hope of lessened toxicity. Both drugs give small but significant gold levels in the skin, which is consistent with the appearance of rashes as a common side effect. There is, however, no direct correlation between gold levels and the occurrence of rashes; patients differ in sensitivity.

Perhaps the most interesting observation is that the joints accumulate appreciably more gold (about twice as much) than the surrounding bone. Since the synovium of the joint is the affected tissue in rheumatoid arthritis, it is significant that the therapeutic metal manages to reach this area. There are indications that affected joints take up more gold than normal joints (29).

When the masses of the various organs are taken into account, about 50 per cent of the administered gold is present in the blood, kidney, liver and skin after 24 hours. There is then a slow decline, with Auranofin-gold being lost slightly more rapidly. After six months, considerably more Myocrisin-gold is retained in the body (30), and gold can be detected many years after administration has been stopped.

When administration is continuous, blood levels stabilise at $30-50 \mu \mathrm{g}$ per $\mathrm{ml}(31,32)$. The actual concentrations vary from individual to individual, and there appears to be no correlation between the therapeutic effect and blood level. Most of the gold from Myocrisin is present in the serum, very little passes into the red cells. There is some evidence that smoking increases the cell-content, the transfer being assisted by the raised levels of cyanide in the blood $(33,34)$. It has also been suggested that the cellcontent may be an indicator of the likelihood of toxic reactions (35). In the serum, the majority ( $80-90$ per cent) of the gold is associated with albumin, and most of the remainder with globulins. The former is lost more rapidly that the latter, so that the balance changes over 3-4 weeks following a single injection (36). For Auranofin, gold in the blood is distributed more evenly between serum and cells, but the latter is cleared slightly more rapidly, so that the equilibrium distribution is not unlike that from Myocrisin $(37,38)$. The ability of Auranofin-gold to pass through the cell wall is probably due to the fact that it, and its primary metabolite, are relatively non-polar molecules.

With both drugs, a small proportion of gold is present in the blood as species with low molecular weight, and this has been described as 'free', 'reactive', or 'unbound' gold (39). However, this form clears rapidly, probably by urinary excretion, and is unlikely to have any therapeutic role.

Of the organs responsible for the clearance of gold from the bloodstream, the kidney develops the highest concentrations (40). The presence of gold in this organ may be responsible for some of the toxic reactions, e.g. proteinurea (loss of protein in the urine) or haematuria (loss of blood into the urine). It has recently been found that gold in urine (rat) is associated with albumin and with another protein of high molecular weight (ca. 150000 daltons) (41). Myocrisin-gold is taken up preferentially (ca. 70 per cent) by the cortex and the lysosomes. The latter can take up large quantities of gold, and can then be seen as dense particles under the electron microscope $(42,43)$. The gold levels are often so high that these cells have been called 'aurosomes'. Within the aurosomes, the gold is associated with sulphur (43-45); it is presumably tightly bound and removed from circulation, but may act as a long-term reservoir. Gel permeation chromatography shows four major species with molecular weights ranging from a few hundred to about 100000 daltons (10). The smallest is possibly a simple complex with cysteine or glutathione, and one of the others is probably a metallothionein complex.

In the liver, gold seems to be taken up initially by the cytosol, forming similar species to those seen in the kidney cortex (10), but passes rapidly to the lysosomes (46). There is some evidence that the orally administered compounds give somewhat lower gold levels in the liver than the in jected drugs, but it is not clear how far this is due to the lower level of absorption of the former.

The patterns of elimination follow those of the uptake by liver and kidney. A large proportion of orally administered Auranofin is eliminated rapidly via the faeces. Some metabolism must occur, however, because radiolabelling experiments show that the sulphur and phosphorus from the drug are readily absorbed, and appear principally in the urine (22). Gold from the injected drugs is passed mainly (ca. 70 per cent) through the kidneys to the urine.

\section{Some Chemistry}

From a chemical point of view, the body is extremely complicated. Even a single fluid, such as blood serum, contains a wide variety of molecules. Many of these are capable, in principle at least, of binding to gold. The chemist is therefore tempted to simplify, to perform reactions in vitro, where only a few chemicals are present at any one time, and some control is possible. However, this poses a different problem. The drugs, once administered, begin to metabolise, to change chemically. Thus, although one may 
take a single biological component such as albumin, it is by no means clear in what form the gold should be. For instance, Auranofin appears to be absorbed as its de-acetylated form; model reactions using the drug itself may no longer be relevant. Many of the earlier in vitro results should therefore be treated with caution.

It is useful first to consider the type of chemistry which might be involved. For the most part, the body is a reducing environment, so the gold is unlikely to be oxidised to the trivalent state. At the same time, there is a sufficient supply of 'soft' ligands to ensure that the gold(I) is stabilised against reduction to the metal. The most likely reactions are therefore those in which one or more ligands are replaced by others.

Gold(I) is predominantly two-coordinate, as in the drugs themselves. A few compounds involving higher coordination numbers are known, but nearly all involve phosphine ligands e.g. $\mathrm{Au}\left(\mathrm{PPh}_{3}\right)_{2} \mathrm{Cl}$ (47) and $\left[\mathrm{Au}\left(\mathrm{PPh}_{2} \mathrm{Me}\right)_{4}\right] \mathrm{PF}_{6}$ (48). Only a few compounds with sulphur ligands are known with three- and four-coordinate gold, and these all have at least one phosphine ligand bound to the gold, e.g. $\mathrm{Au}\left(\mathrm{PPh}_{3}\right)_{2} \mathrm{SCN}$ (49), $\mathrm{Au}\left(\mathrm{PPh}_{3}\right)_{3} \mathrm{SCN}(50,51),\left(\mathrm{R}_{3} \mathrm{PAu}\right)_{2} \mathrm{MS}_{4}(\mathrm{M}=\mathrm{Mo}, \mathrm{W})(52)$. As seen earlier, the phosphine ligands in the drugs are eliminated quite rapidly, and it is unlikely that phosphine complexes play any large role in the long-term therapeutic effect. It is equally unlikely that any significant biological species will show coordination numbers greater than two for the gold. However, the ability of gold(I) to expand its coordination shell is important in reactions in which one ligand is replaced by another. Such reactions usually involve a three-coordinate intermediate:

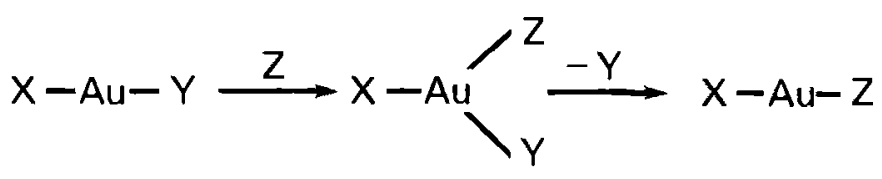

Since the incoming ligand, $\mathrm{Z}$, has ready access to the gold atom, and can be bound easily, such reactions are very rapid and will probably be the major means by which the gold atom 'changes partners' in the biological system.

A wide variety of potential ligands is available in vivo, with oxygen, nitrogen, and sulphur atoms as possible binding sites for the gold atom. Since gold(I) has a strong preference for 'soft' ligands, it is generally assumed that any major, long-lived species will involve sulphur-containing groups of the thiolate type; thioethers bind much more weakly to gold, and are readily replaced. Most studies have therefore concentrated on the reactions of the drugs with naturally occurring thiols such as cysteine and glutathione.

Myocrisin and other gold(I) thiolates undergo facile ligand-exchange reactions with a variety of thiols, including thiomalate and cysteine $(10,53)$. The products obtained depend on the composition of the mixture, but in the presence of an excess of the thiol the principal product is almost certainly the monomeric species $\mathrm{Au}(\mathrm{SR})_{2}^{-}$. There is spectroscopic and EXAFS evidence for such species in which the SR group comes from thiomalate, cysteine, or penicillamine, and the benzenethiolate derivative has recently been characterised by X-ray crystallography $(45,54-$ 56). A range of mixed-ligand polymeric species is formed when the amounts of the gold(I) thiolate and the added thiol are about equal. Auranofin also undergoes facile thiol exchange, e.g. with cysteine derivatives (57).

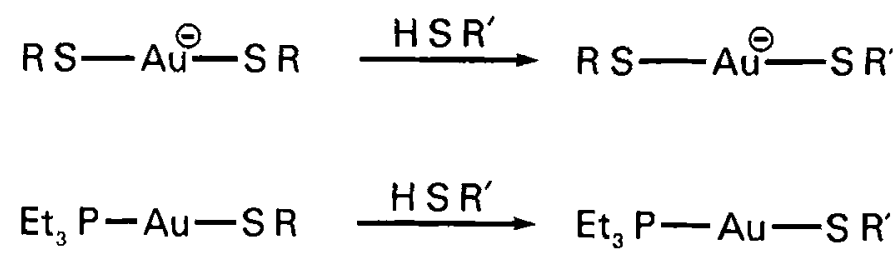

In the blood stream, much gold is bound to albumin. Serum albumin, and the bovine analogue which is often used in model experiments, is a very large protein (molec. ular weight about 65000 ). It contains 35 cysteine residues but most of these are paired together as the oxidised cys. tine form, i.e. the SH-groups have joined together to form S-S bonds (Figure 2). Only one SH-unit is present (Cys34) and this appears to be situated in a cleft of the globula structure about $950 \mathrm{pm}$ from the surface (58). Some ver: elegant studies using spectroscopic, chromatographic ani radiolabelling methods have shown that gold from Myo crisin binds to this site (59). When the albumin is in excess as in the blood, a 1:1 complex is formed analogous to th $\mathrm{Au}(\mathrm{SR})_{2}{ }^{-}$species mentioned above:

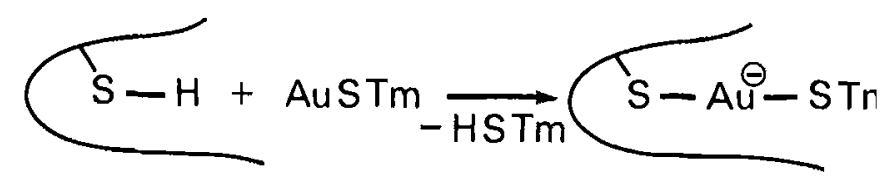




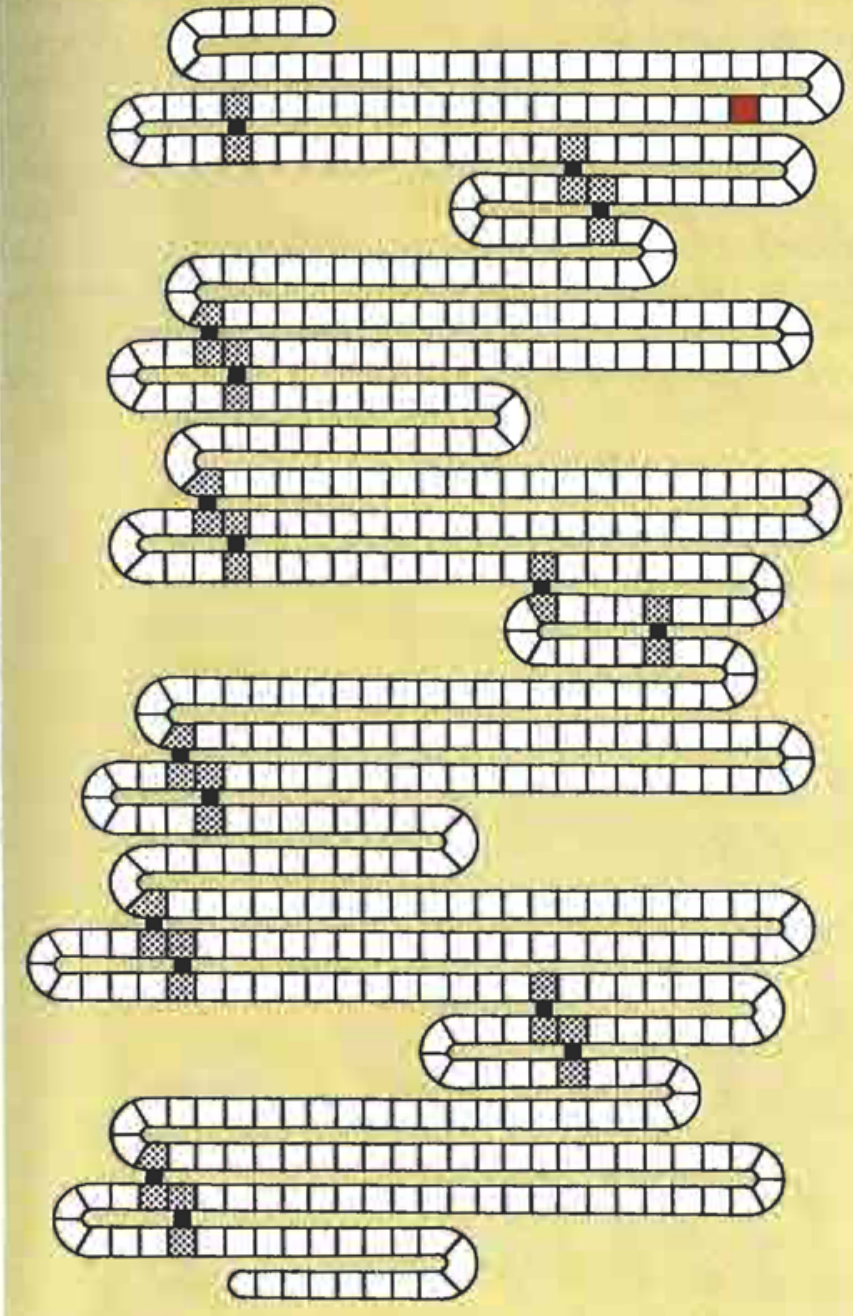

Fig. 2 Schematic representation of the albumin sequence, showing the seventeen cystine $S-S$ linkages and the unique cysteine unit

This complex is very stable and results in tight binding of the gold. In vivo studies show that the thiomalate ligand is lost from the blood much more rapidly than the gold (60), presumably from thiolate-exchange reactions with cysteine, glutathione, or other naturally occurring thiols.

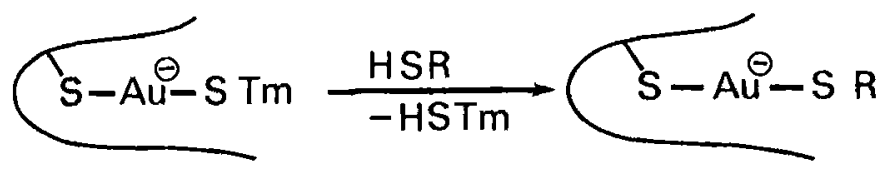

Auranofin also reacts with albumin, at the same site, with displacement of the thioglucose (61):

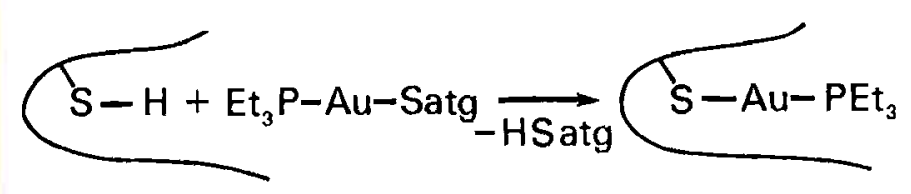

This is consistent with the much more rapid elimination of the thioglucose than the gold from the blood-stream, as shown by experiments with the radio-sulphur labelled drug (in rats) (56). In vitro experiments with blood (from rats or dogs) also shown very different binding patterns for gold and sulphur (22). It is known that the phosphine is eliminated more rapidly than the gold, and in vitro experiments confirm the separation of the phosphine from the gold (22). It is therefore likely that secondary reactions occur, in which endogenous thiols displace the phosphine:

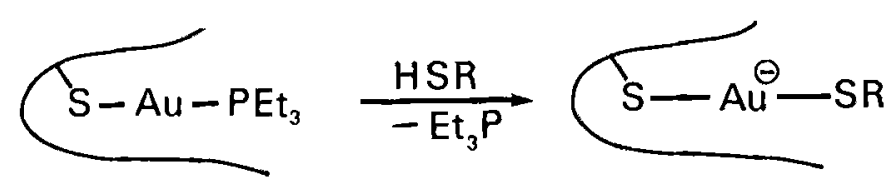

There is little Myocrisin-derived gold in the red blood cells except in patients who smoke $(34,35)$. This effect is attributed to raised levels of cyanide in the serum which somehow assists the gold to pass through the cell wall. In model experiments with Myocrisin and $\mathrm{Au}(\mathrm{SR})_{2}{ }^{-}$(e.g. HSR $=$ glutathione), it has been shown $(62,63)$ that a gold-sulphur bond can be broken by cyanide to give mixed-ligand species RSAuCN'. These species undergo facile thiolate exchange:

$\mathrm{RS}-\mathrm{AU}-\mathrm{SR} \underset{-\mathrm{CN}}{-\mathrm{CN}^{-}} \mathrm{RS}-\mathrm{A} \mathrm{U}^{\ominus}-\mathrm{CN}$

Presumably, relatively small molecules like GluSAuCN are able to transport gold more easily across the cell membrane. NMR evidence suggests that, in the blood cells, gold from Myocrisin or Auranofin binds to glutathione, but the species formed has not been identified (64). 
In kidney and liver cells, gold is found in the cytoplasm, and there is evidence (10) for the presence of a cysteine complex of the type Au(SR) ${ }_{2}^{-}$. Several other gold-containing components are present, of which one has been identified as metallothionein. Metallothionein is a protein containing 61 amino-acid residues, of which 20 are cysteine. This abundance of thiol groups gives it a powerful capacity to bind the 'softer' metals, and natural metallothionein usually contains zinc, cadmium, and some copper. In the fully metallated state, one molecule of metallothionein contains seven metal atoms. In test-tube reactions with Myocrisin, provided the Myocrisin is not in excess, up to ten gold atoms can replace the divalent metal, with zinc being replaced in preference to cadmium (65). At the same time, all the thiomalate is liberated. EXAFS studies show that, as usual, the gold is linearly coordinated to two sulphur atoms (see below):
Curiously, Auranofin does not react with metallothione in in vitro (66), although cultured epithelial cells will take Auranofin-gold into their metallothionein (67). This underlines the need to use the drug metabolites in model experiments, rather than the drugs themselves. Presumably the acetylthioglucose cannot be displaced by the cysteine residue of the metallothionein, either for thermodynamic or steric reasons. It is not known whether the deacetylated form of the drug will react directly with metallothionein. However, this is probably not relevant either since, by the time the gold reaches the kidney, it is bound to albumin, and may even have lost the phosphine ligand.

\section{Anti-tumour Agents}

Some gold complexes have been shown to be toxic to various tumour cells in culture, e.g. Auranofin and $\mathrm{Au}(\mathrm{CN})_{2}^{-}$, but these are not active in vivo $(68,69)$. By analogy with the
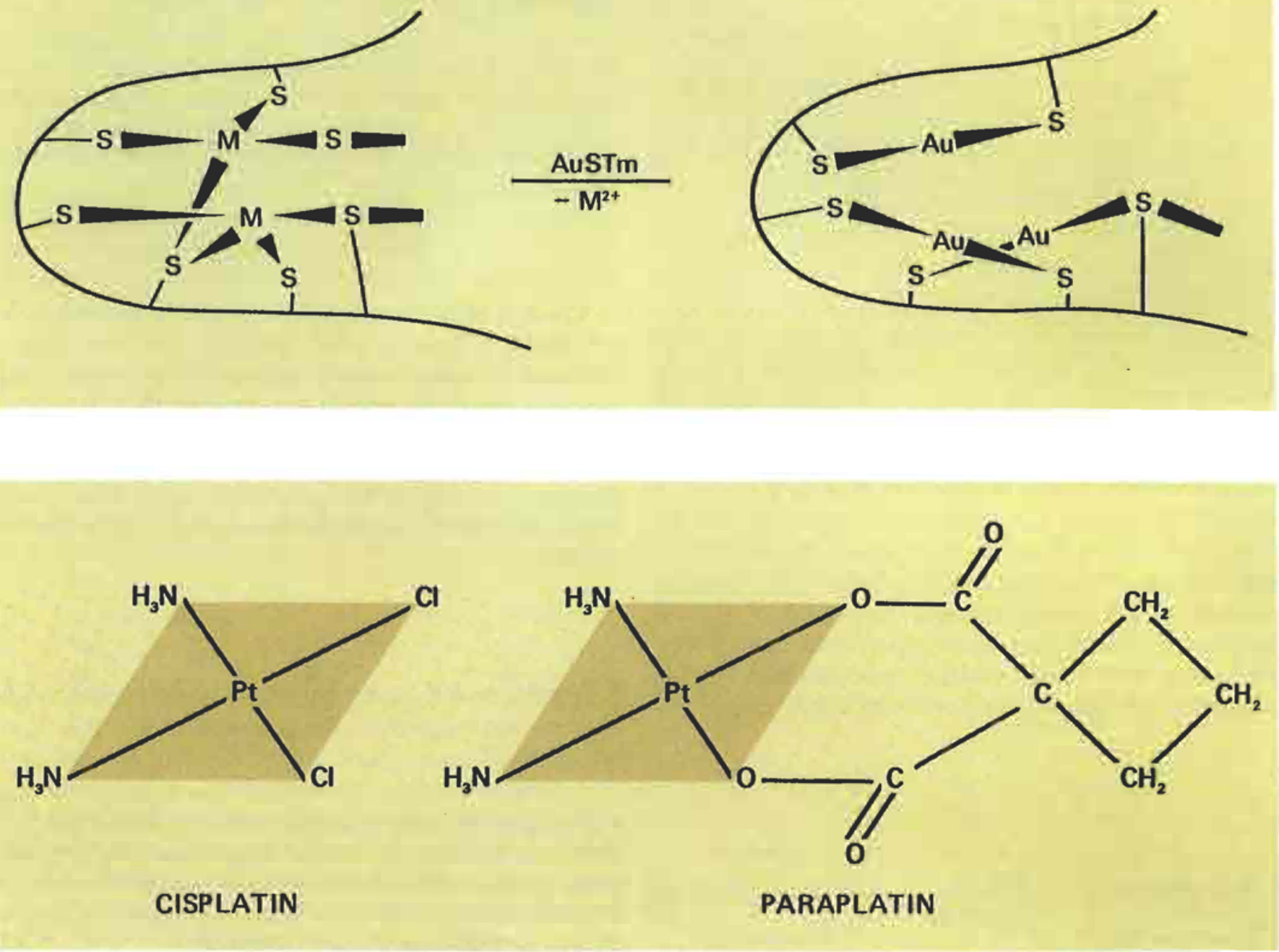


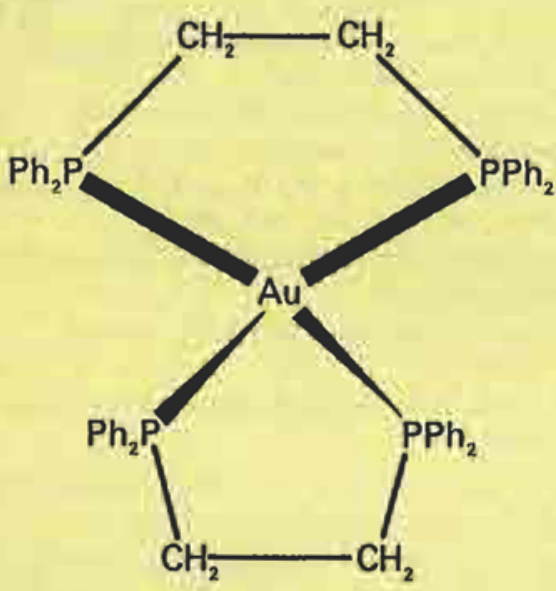

Au(dppe) $2^{+}$

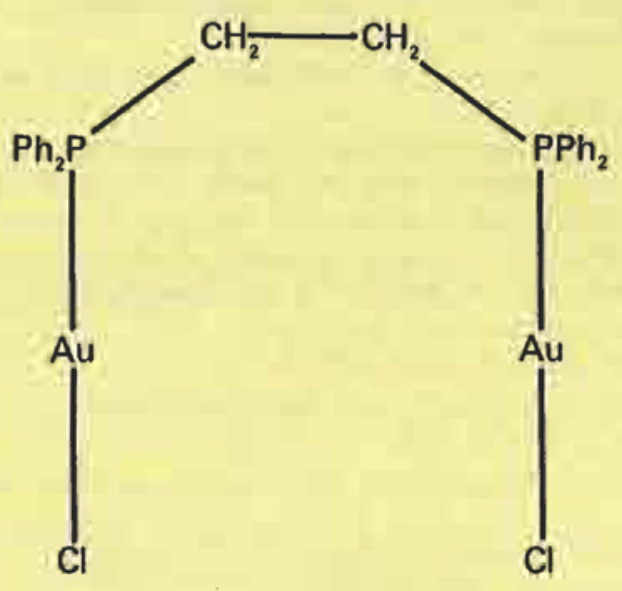

ClAu(dppe)AuCl clinically successful platinum-based drugs, such as cis$\mathrm{PtCl}_{2}\left(\mathrm{NH}_{3}\right)_{2}$ (cisplatin) and $\mathrm{Pt}\left[\left(\mathrm{O}_{2} \mathrm{C}\right)_{2} \mathrm{C}_{4} \mathrm{H}_{6}\right]\left(\mathrm{NH}_{3}\right)_{2}$ (paraplatin), it might be thought that gold(III) would be more suitable than gold(I). Gold (III) is isoelectronic with platinum(II), and forms similar square-planar complexes. However, many gold(III) complexes are readily reduced to gold(I) or gold metal, which would probably mean that they would never reach the desired site and would instead be toxic. It will be necessary to choose the ligands very carefully to prevent this. The organometallic complexes $\mathrm{Au}\left(\mathrm{CH}_{3}\right)_{2} \mathrm{Cl}_{2}^{-}$and $\left(\mathrm{H}_{3} \mathrm{C}\right)_{2} \mathrm{Au}(\mathrm{SCN})_{2} \mathrm{Au}\left(\mathrm{CH}_{3}\right)_{2}$ are effective in anti-tumour tests (70).

Very recently a new type of complex has been found to show great promise (4). This is a four-coordinate gold(I) complex $\left[\mathrm{Au}(\mathrm{dppe})_{2}\right] \mathrm{Cl}\left(\mathrm{dppe}=\mathrm{Ph}_{2} \mathrm{PCH}_{2} \mathrm{CH}_{2} \mathrm{PPh}_{2}\right.$ ). The more conventional compound $\mathrm{ClAu}(\mathrm{dppe}) \mathrm{AuCl}$ is also active, but it has been shown that in blood it readily undergoes disproportionation to form $\mathrm{Au}(\mathrm{dppe})_{2}{ }^{+}$. The corresponding silver(I) and copper(I) complexes are also active, as is the ligand itself. The metal complexes seem to be rather more effective than the pure ligand, and it is likely that the metal serves as a protective carrier for the ligand, ensuring that it arrives intact at the active site. This is a neat reversal of the situation for the anti-arthritic drugs.

\section{Conclusion}

Drugs containing gold are effective agents against rheumatoid arthritis, but their mode of action is still unclear. The pattern of distribution of gold in the body pro- duced by their use is reasonably well established, and is significantly different from those of the other components of the drugs. Gold is retained considerably longer than these components, and it seems certain that the therapeutic activity is due to the gold.

Some progress has been made in understanding the biochemistry of gold, and complexes with albumin and metallothionein have been characterised. These studies are at an early stage, but have emphasised the need to use the metabolites of the drugs, rather than the drugs themselves.

\section{References}

1 G.J.Higby, Gold Bull., 1982, 14, 130

2 K. Lande, Munch. Med. Wochenschr., 1927, 74, 1123; J. Forestier, Bull. Mem. Soc. Med. Hop. Paris, 1929, 323; T.N. Fraser, Ann. Rheum. Dis., 1945, 4, 71; Empire Rheumatism Council, ibid, 1961, 20, 315; Amer. Rheum. Ass., Arth. Rheum., 1973, 16, 353

3 B.M. Sutton, Gold Bull., 1986, 19, 15.

4 C.K. Mirabelli et al, 20th Great Lakes Regional Amer. Chem. Soc. Mtg., Milwaukee, 1986, Abstr. 204, 243, 244; Eur. Pat. Appl., 1985, 05303851.1 (Smith Kline Beckman Corp.)

5 R.H. Freyberg, M. Ziff and J. Baum, in 'Arthritis and Allied Conditions' J.L. Hollander and D.J. McCarty (eds.), Lea and Febiger, Philadelphia, 8th Ed,, 1972, p. 455

6 N. Zvaifler, in 'Arthritis and Allied Conditions' D.J. McCarty (ed.), Lea and Febinger, Philadelphia, 9th Ed., 1979, p. 364

7 C.F. Shaw, Inorg. Perspect Biol. Med., 1979, 2, 287

8 P.J. Sadler, Struct. Bonding (Berlin), 1976, 29, 171 
9 F.E. Moore, R.J. Othman and B. March, J. Amer. Pharm. Ass., $1951,15,184$

10 C.F. Shaw, G. Schmitz, H.O. Thompson and P. Witkiewicz, J. Inorg. Biochem., 1979, 10, 317

11 K. Brown, R.V. Parish and C.A. McAuliffe, J. Amer. Chem. Soc., $1981,103,4943$

12 M.A. Mazid, M.T. Razi, P.J. Sadler, G.N. Greaves, et al., J. Chem. Soc., Chem. Commun., 1980, 1261

13 D.T. Hill, B.M. Sutton, A.A. Isab, M.T. Razi, et al., Inorg. Chem., $1983,22,2936$

14 A.K.H. Al-Sa'ady, C.A. McAuliffe, K. Moss and R.V. Parish, J. Chem. Soc, Dalton Trans., 1984, 1609

15 I.G. Dance, Inorg. Chim. Acta, 1977, 25, L17

16 I.G. Dance, L.J. Fitzpatrick, A.D. Rae and M.L. Scudder, Inorg. Chem., 1983, 22, 3785

17 I.G. Dance, L.J. Fitzpatrick and M.L. Scudder, Inorg. Chem., 1984 23, 2276

18 R.C. Elder, K. Ludwig, J.N. Cooper and M.K. Eidsness, J. Amer. Chem. Soc., 1985, 107, 5024

19 S.R. Rudge, D. Perrett, A.J. Swannell and P.L. Drury, J. Rheum., $1984,11,150$

20 D.T. Hill and B.M. Sutton, Cryst. Struct Commun., 1980, 9, 679

21 K. Tepperman, R. Finer, S. Donovan, R.C. Elder, et al., Science, $1984,225,430$

22 A.P. Intoccia, T.L. Flanagan, D.T. Walz, L. Gutzail, et al., J. Rheumatol., 1982, 9, (Suppl. 8), 90

23 S.M. Cottrill, H.L. Sharma, R.V. Parish and C.A. McAuliffe, (unpublished data)

24 I. Jaffe, Ann. Rheum. Dis., 1963, 27, 14

25 F. Arrigoni-Martelli, E. Bramm and L. Binderup, Europ. J. Rheum. Inflamm., 1978, 1, 197

26 E. Jellum, E. Munthe, G. Guldal and J. Aaseth, Ann. Rheum. Dis., $1980,39,155$

27 E. Munthe, E. Jellum, Scand. J. Rheum., 1908, Suppl. 33, 21

28 See e.g. N.L. Gottleib, Scan. J. Rheum., 1984, 10, (Suppl. 15); idem, Bull. Rheum. Dis., 1977, 27, 912; A.J. Lewis and D.T. Walz, Prog. Med. Chem., 1982, 19, 1; D.E. Furst and S.H. Dromgoole, Clin. Rheumatol., 1984, 3, (Suppl. 1), 17

29 B. Vernon-Roberts, J.L. Dove, J.D. Jessop and W. Henderson, Ann. Rheum. Dis., 1976, 35, 477

30 R.C. Blodgett, M.A. Heuer and R. Peit rusko, Semin. Arth, Rheum., $1984,13,25$

31 R.C. Gerber, H.E. Paulus, R. Bluestone and M. Lederer Arth. Rheum., 1972, 15, 622

32 A. Lorber, R.L. Cohen C. Chang and H.E. Anderson, Arth. Rheum., 1968, 11, 170

33 G.G. Graham, T.M. Haavisto, H.M. Jones and C.D. Champion, Biochem. Pharm., 1984, 33, 1257

34 D. Lewis, H.A. Capell, C.J. McNeill, M.S. Iqbal, et al., Ann. Rhem. Dis., 1983, 42, 566

35 S.M. Pederson and P.M. Graabeek, Ann. Rhem. Dis., 1980, 39, 576

36 E.N. Ghadially, A.F. Ortschak and D.M. Mitchell, Ann. Rheum. Dis., 1976, 35, 67

37 D.T. Walz, D.E. Griswold, M.J. DiMartino and E.E. Bumbier, J. Rheumatol., 1979, 6 (Suppl. 5), 56

38 D.T. Walz, M.J. DiMartino, D.E. Griswold, A.P. Intoccia and T.L. Flanagan, Amer. J. Med., 1983, 74, 90

39 A. Lorber, Agents and Actions, 1981, Suppl. 8, 539

40 E.G. McQueen and P.W. Dykes, Ann. Rheum. Dis., 1969, 28, 437; W.D. Block, O.H. Buchanan and R.H. Freyberg,
J. Pharm. Exp. Theor., 1942, 76, 355; N.L. Gottlieb, P.M. Smith and E.M. Smith, Arth. Rheum., 1972, 15, 16; D. Kamel, D.H. Brown, J.M. Ottway, W.E. Smith, et al., Agents Actions, 1978, 8, 546

41 C.F. Shaw, N. Schaeffer-Memmel and D. Krawczak, J. Inorg. Biochem., 1986, 26, 185

42 F.N. Ghadially, J. Rheumatol., 1979, Suppl. 5, 45

43 H. Nakamura and M. Igarashi, Ann. Rheum. Dis., 1977, 36, 209

44 R.C. Elder, M.K. Eidsness, M.J. Heeg, K.G. Tepperman, et al., Amer. Chem. Soc. Symp. Ser, 1983, 209, 385

44 R.C. Elder, Proc. Symp. Bioinorg. Chem. Gold, SK\&F Laboratories, Philadelphia, 1983, 124

46 K.J. Lawson, C.J. Danpure and D.A. Fyfe, Biochem. Pharmacol, $1977,26,2417$

47 N.C. Baenziger, K.M. Dittemore and J.R. Doyle, Inorg. Chem, $1974,13,805$

48 R.C. Elder, E.H. Kelle-Zeiher, M. Onady and R.R. White, J. Chem. Soc., Chem. Commun., 1981, 900

49 J.A. Muir, M.M. Muir and S. Arias, Acta Cryst., 1982, B38, 1318

50 J.A. Muir, M.M. Muir, S. Arias, C.F. Campana and S.K. Dwight, Acta Cryst., 1982, B38, 2047

51 J.A. Muir, M.M. Muir, S. Arias, P.G. Jones and G.M. Sheldrick, quoted by P.G. Jones, Gold Bull., 1983, 16, 114

52 J.C. Hoffmann, R.S. Roth and A.R. Seidle, J. Amer. Chem. Soc, 1976, 98, 4340; E.M. Kinsch and D.W. Stephan, Inorg. Chim. Acta, $1985,96, \mathrm{~L} 87$

53 A.A. Isab and P.J. Sadier, J. Chem. Soc., Dalton Trans., 1982, 135

54 C.F. Shaw, Proc. Symp. Bioinorg. Chem. Gold, SK\&F Laboratories, Philadelphia, 1983, 98

55 P.A. Bates and J.M. Waters, Acta. Cryst., 1985, C41, 862

56 S.M. Cottrill, L.S. Moore, R.V. Parish and C.A. McAuliffe, (unpublished data)

57 N.A. Malik, G. Otiko, M.T. Razi and P.J. Sadler, Proc. Symp. Bioinorg. Chem. Gold, SK\&F Laboratories, Philadelphia, 1983, 82

58 H.H. Hull, R. Chang and L.J. Kapian, Biochem. Biophys. Acta, $1975,400,132$

59 C.F. Shaw, N.A. Schaeffer, R.C. Elder and M.K. Eidsness, et al. J. Amer. Chem. Soc., 1984, 106, 3511

60 E. Jellum, E. Munthe, G. Guldal and J. Aaseth, Ann. Rheum. Dis., $1980,39,155$

61 M.T. Coffer, C.F. Shaw, M.K. Eidsness, J.W. Watkins and R.C. Elder, Itorg. Chem., 1986, 25, 333

62 G. Lewis and C.F. Shaw, Inorg. Chem., 1986, 25, 58

63 G.G. Graham, J.R. Bales, M.C. Grootveld and P.J. Sadier, J. Inorg. Biochem., 1985, 25, 163

64 M.T. Razi, G. Otiko and P.J. Sadler, Amer. Chem. Soc. Symp. Ser., 1983, 209, 371

65 J.E. Laib, C.F. Shaw, D.H. Petering, M.K. Eidsness, et al., Biochem., 1985, 24, 1977

66 C.F. Shaw and J.E. Laib, Inorg. Chim. Acta, 1986, 123, 197

67 A. Glennas et al., Abstr. 2nd Metallothionein Mtg., Zurich, 1985, 46; 20th Great Lakes Regional Amer. Chem. Soc. Mtg., Milwaukee, 1986, (Abstr.) 205

68 T.M. Simon, D.H. Kunishima, G.J. Vibert and A. Lorber, Cancer Res., 1981, 41, 94

69 C.K. Mirabelli, R.K. Johnson, C.M. Sung, L. Faucette, et al., Cancer Res., 1985, 45, 32

70 Nat. Cancer Inst., quoted by S.J. Berners-Price and P.J. Sadler in 'Frontiers in Bioinorganic Chemistry', A.V. Xavier (ed.), VCH Verlag, Weinheim, 1956, p. 376 